\title{
A Study on Development Scale and Spatial Economic Structure of the Urban Agglomerations of Shandong Province
}

\author{
(SUBMITTED BUT NOT PRESENTED)
}

\author{
XIE Haïjun \\ Qingdao Binhai University \\ Qingdao,P.R.China \\ Xiehj2008@163.com
}

\author{
WANG Wei \\ Qingdao Binhai University \\ Qingdao,P.R.China \\ 988415@qq.com
}

\begin{abstract}
Urban agglomeration development is an important embodiment in regional competitiveness improvement. To explore the actual urban agglomeration development of Shandong Province, this essay studies the urban agglomeration scope by analyzing urban primacy ratio and scale fractal distribution, analyzes the spatial distribution of urban agglomeration by attraction model and analyzes the spatial economic relation and urban function of the urban agglomeration by further application of urban flow intensity and urban function index. After an overall exploration of the spatial relation, the author has reached the conclusion that urban agglomerations of Shandong Province tend to be outwardlooking, the development structure is far from reasonable and urban function division needs further improvement.
\end{abstract}

Keywords—urban agglomerations; urban function; scal; spatial economic relation

\section{INTRODUCTION}

As the main feature in the national regional economic development in the 21st century, urban agglomeration is playing an increasingly important role in our national regional economic integration and urbanization. Lying at the east coast of China and the lower reach of Yellow Sea with east of Shandong peninsular stretching into the Yellow Sea, facing Liaodong peninsular across the Bohai Strait in the north, adjacent to Korea and Japan, facing Koran peninsular across Yellow Sea in the east, facing the broad Yellow Sea in the southeast and looking beyond East Sea and islands of South Japan, Shandong Province covers a total area of 157,100 square kilometers and a sea area of 170,000 square kilometers. Its permanent resident population reached 96,850, 000 at the end of 2012 with 17 cities and 137 counties (including counties, county-level cities and districts) under its juris diction. Its annual provincial GDP in 2012 was 5.001324 trillion RMB taking up $9.63 \%$ in China's total GDP and making it the top three provinces in economic power. Shandong has formed its "one group-one circle-one belt" urban agglo meration in spatial structure, i.e. Shandong peninsular urban group, Jinan metropolis circle and South Shandong Economic Belt. To confirm whether urban agglomeration has come into being currently in Shandong Province, analyze the spatial functional structure and economic relation among different cities in the urban agglomeration and view the development of Shandong urban agglomeration empirically, the final goal is to make sure that Shandong urban agglomeration may develop a healthy and sustainable manner and becomes more competitive among urban groups in order to make itself an important growth pole in the regional even national economic development.

Relevant overseas urban agglomeration study has made breakthrough and rewarding development on urban agglomeration spatial structure after the Second World War. Research during this period mainly focused on the special interaction, spatial structure evolutionary phase, spatial structure evolutionary mode and spatial evolutionary mechanism of the urban agglomeration.

At the beginning of the 1950s, O.Duncan [1] and F.Perroux[2], conducted further study on urban system; the research on urban agglomeration spatial structure and effect made by E.L.Ullman[3],Jean, Gottmann[4]and McGee[5] has profound influence; J.Friedmann[6] , Gustavo Garza [7] , G.Mulgan[8], A llan D.Wallis and Tomita Kazuaki[9] made a systemic study on urban agglomeration development phase and factors affecting spatial congregation.

Research of the urban agglomeration spatial layout in China started in the 1980s.Yu Hongjun and Ning Yuemin (1983) were the first to introduce Gottman idea to China using the translated term "megalopolis belt" [10]; Zhou Yixing (1988) put forward the conceptual system of Chinese urban areas early in effort to integrate the area concept of Chinese cities with the international general conception by learning fro $m$ the spatial unit system of different scales of the western cities [11]. Lu Dadao (1984) put forward the theory of "dot to axle" and "T" shaped pattern of land resources development and economic layout of China[12]. According to the regional distribution of urban combination, Yao Shimou divided the urban agglomeration as block city group, banded city group and city group in radial or ring pattern and spatial layout of the urban agglomeration was divided for the first time domestically [13]. By analy zing the regional structure of urban agglomeration economic space, Zhu Yingming (2003) came 
out with the layout of urban spatial distribution shaped in ">", " $\triangle$ "and"H”[14].

Yao Shimou and ChenShuang (1998) conducted a study on the basic evolutionary features, driving force and functional change of urban space of the Yangtze River Delta as well as the evolutionary trend of its urban space[15]. Zhang Gongsheng (2009) made a conceptual summary of the domestic urban agglomeration by exploring the difference and connection among urban interlocking region, urban compact district, urban circle, urban system and megalopolis and listed the $23 \mathrm{urban}$ groups formed or being formed in China from the perspective of regional planning and academic discussion[16].Through analyzing and studying the development situation of Bohai megalopolis, Shi Wujun (2011) held the opinion that urban agglomeration develop ment should depend on intercity transportation and centered at cities of different levels to promote the spatial integrated development of urban agglomeration following the spatial mode of " urban district to city circle to urban group"[17].

The study of urban agglomerations of Shandong Province mainly focuses on the study of Shandong peninsular urban groups. Sun Jinfang[18], Xie Fuhui[19], Sun Xiaona[20] and Wang Xinna[21] emphatically studied the revolution of spatial distribution of Shandong peninsular urban groups, is sues of the current spatial layout and means to improve the spatial layout of Shandong peninsular urban groups. After literature review, no research has been made on the spatial structure of Shandong peninsular urban agglomeration; therefore, this essay may contribute to this area.

\section{SCALE AND SPATIAL DISTRIBUTION OF URBAN AgGlOMERATIONS IN SHANDONG PROVINCE}

\section{A. General features of urban agglomerations of Shandong Province}

There are 17 prefecture-level cities in Shandong Province. During the study, we use the non-agricultural population of the urban district to represent the scale of the city and city scale of the urban agglomeration of Shandong Province is showed in TABLE.1. The lack of small cities in Shandong urban agglomerations leads to the uneven distribution in terms of urban structural system.

\section{B. Primacy ratio}

The concept of urban primacy ratio was proposed by M.Jefferson in 1939. At the present, it is generally held that urban primacy ratio includes 2 urban index, 4 urban index and 11 urban index[22]. From the data showed in TABLE.1, it can work out 2 urban index S2=1.03, 4 urban index S4=0.49 and 11 urban index $S 11=0.50$. According to order-scale theory, the ideal 4 urban index and 11 urban index are 1 and the 2 urban index is 2[23].Primacy index of urban agglomeration of Shandong Province is obviously smaller than that of the ideal, which tells that urban agglomerations in Shandong Province are not distributed according to primacy index.
CITY SCALE AND GRADE OF THE URBAN AGGLOMERATIONOF SHANDONG PROVINCE

\begin{tabular}{|c|c|c|c|c|}
\hline No. & city & city scale & scale grade & city grade \\
\hline 1 & Ji'nan & 228.57 & super large & sub-provincial \\
\hline 2 & Qingdao & 222.87 & super large & sub-provincial \\
\hline 3 & Zibo & 135.09 & megalopolis & prefecture-level \\
\hline 4 & Yantai & 111.41 & megalopolis & prefecture-level \\
\hline 5 & Weifang & 76.92 & big & prefecture-level \\
\hline 6 & Dongying & 60.93 & big & prefecture-level \\
\hline 7 & Zaozhuang & 58.16 & big & prefecture-level \\
\hline 8 & Taian & 57.70 & big & prefecture-level \\
\hline 9 & Jining & 51.34 & big & prefecture-level \\
\hline 10 & Linyi & 49.48 & medium & prefecture-level \\
\hline 11 & Weihai & 46.36 & medium & prefecture-level \\
\hline 12 & Laiwu & 40.57 & medium & prefecture-level \\
\hline 13 & Dezhou & 37.68 & medium & prefecture-level \\
\hline 14 & Liaocheng & 32.74 & medium & prefecture-level \\
\hline 15 & Rizhao & 31.39 & medium & prefecture-level \\
\hline 16 & Binzhou & 27.01 & medium & prefecture-level \\
\hline 17 & Heze & 24.30 & medium & prefecture-level \\
\hline
\end{tabular}

Data from: China City Statistical Yearbook (2012)

\section{Scale distribution}

The From the logarith $m$ chart of the ordered number of urban population scale of Shandong urban agglomerations as showed in Fig.1, it can clearly tell that due to the closeness of the two super large cities, population of which is higher than other cities, Jinan and Qingdao find themselves in the leading position but there is no big difference among other cities. In other words, there is no obvious polar city in the urban agglomerations of Shandong Province.

Using the logarith $m$ of the ordered number of the urban population scale of urban agglomerations as independent variable and the logarithm of the non-agricultural population of the city as dependent variable to have linear-regression analysis by $\mathrm{Y}=\mathrm{a}+\mathrm{bX}$,

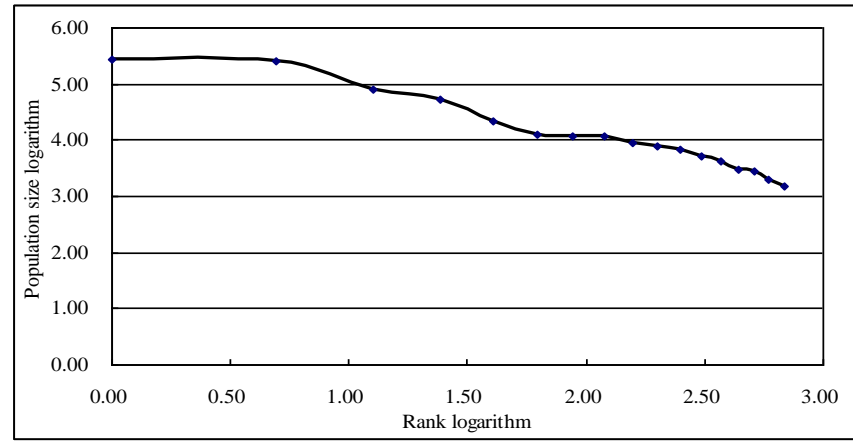

Fig.1 Logarithm chart of the ordered number of urban population scale urban agglomerations of Shandong province 
T ABLE.2 QUANTITATIVE ANALYSIS RESULT BY REGRESSION EQUATION

\begin{tabular}{ccccc}
\hline Variable & Coefficient & Std.Error & t-Statistic & Prob. \\
\hline $\mathrm{C}$ & 5.7332 & 0.0912 & 62.8413 & 0 \\
$\mathrm{X}$ & -0.8357 & 0.0431 & -19.3837 & 0 \\
\hline & Adjusted R-squared & 0.9591 & \\
& Durbin-Watson stat & 1.5018 & \\
& F-statistic & 375.7290 & \\
& Prob(F-statistic) & 0.0000 & \\
\hline
\end{tabular}

see the analysis result in TABLE. 2. The specific expression of regression equation is $\mathrm{Y}=5.7332-0.8357 \mathrm{X}$, $\mathrm{b}=0.8537$ and smaller than 1 . It can tell that high ranked cities are not in the monopoly position in the urban agglomeration.

\section{Urban spatial layout based on attraction model}

In Attraction model $\mathrm{T}_{\mathrm{ij}}=\mathrm{K}\left(\mathrm{P}_{\mathrm{i}} \mathrm{P}_{\mathrm{j}} / \mathrm{d}_{\mathrm{ij}} \mathrm{b}\right)$, of which, Tij represents the attractiveness, $i$ is the population, $K$ is the coefficient, is the distance between the two places and $\mathrm{b}$ is the distance friction coefficient. In this model, Pi means the nonagricultural population of the urban district and dij is measured by the straightline shortest distance (spatial straightline distance). K's value has nothing to do with the binary relation of the calculation, usually it takes 1 and $b$ takes 2. Attraction matrix can be formed by calculating the attraction value of each city and other cities.

After getting the attraction matrix, choose the biggest attraction for each city to figure out the relatively most attractive city for each city, connect these two cities with a line in the map and finally work out the connection line distribution map of the urban maximum attraction as showed in Fig.2

From the Fig.2, it can tell that urban groups in Jinan have more obvious core influence than that of peninsular urban groups centering Qingdao. Spatial relation between south Shandong and Jinan and Qingdao is pretty weak.

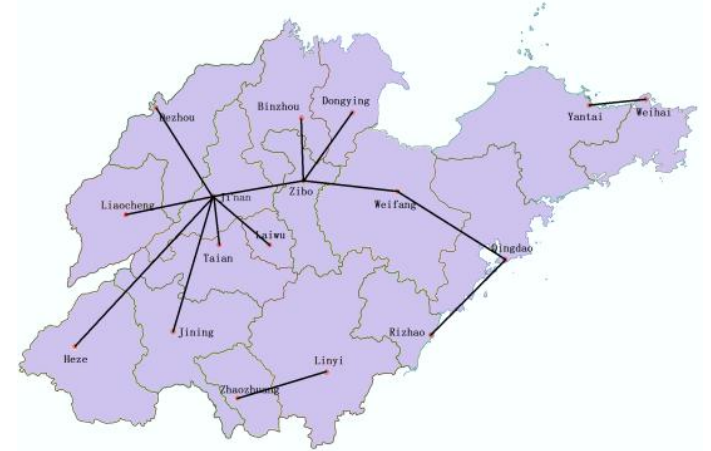

Fig.2 Attraction sketch map of cities of Shandong urban agglomerations

\section{SPATIAL ECONOMIC RELATION AND FUNCTIONAL STRUCTURAL ANALYSIS OF SHANDONG URBAN AGGLOMERATIONS}

\section{A. Method and data}

Urban flow intensity refers to energy produced by the urban outward function (assembling and radiating) and the quantitative relation between cities and city and rural areas in urban relations, which is the quantitative index explaining the relation between cities and the outside world. Its calculation formula is: $\mathrm{F}=\mathrm{N}^{*} \mathrm{E}$ in which, $\mathrm{F}$ is urban flow intensity and $\mathrm{N}$ is urban functional benefit, the actual influence produced by the outward energy of urban units and $\mathrm{E}$ is the urban outward energy. In view of the representativeness and possibility of the index selected, choose the urban employed people of different industries as urban function index and see if the city has urban outward function, which depends on the location quotient of the employed people of some area[24].Location quotient of the employed people of department $\mathrm{j}$ of city $\mathrm{i}$ is Lqij.

$$
L q_{i j}=\frac{G_{i j} / G_{i}}{G_{j} / G} \quad(\mathrm{i}=1,2,3, \cdots \cdots \mathrm{n} ; \mathrm{j}=1,2,3, \cdots \cdots \mathrm{m})
$$

In Formula(1), Gij is the employed people of department j of city $i$; $\mathrm{Gi}$ is the total employed population of city $\mathrm{i} ; \mathrm{Gj}$ represents the employed people of department $j$ of the local area and $\mathrm{G}$ is the total employed people of the city. If Lqij< 1, department $\mathrm{j}$ of city $\mathrm{i}$ has no outward function, i.e. Eij= 0; if Lqij> 1, department $j$ of city $i$ has potential outward function. Because the ratio of department $j$ assigned by the total employed people of city $i$ exceeds the assigned ratio where the city locates, in other words, department $i$ is the specialized department in city $\mathrm{j}$ in the area and it is able to provide service for area beyond the city. Therefore, the outward function of department $j$ of city $i$ is(2):

$$
E_{i j}=G_{i j}-G_{i}\left(\frac{G_{j}}{g}\right)
$$

Ei,the total outward function of $m$ departments of city $i$,

$$
\text { is(3): } E_{i}=\sum_{j=1}^{m} E_{i j}
$$

$\mathrm{Ni}$, the function efficiency of city $\mathrm{i}$ indicated with average GDP of the employed people, i.e.

$$
N_{i}=\frac{G D P_{i}}{G_{i}}
$$

In Formula (4), GDPi is the GDP of city i.Fi, urban flow intensity of city $\mathrm{i}$, is(5):

$$
F_{i}=N_{i} \times E_{i}=\left(\frac{G D P_{i}}{G_{i}}\right) \times E_{i}=G D P_{i} \times\left(\frac{E_{i}}{G_{i}}\right)=G D P_{i} \times K_{i}
$$

In Formula(5), $\mathrm{Ki}$ is the ratio of outward function value to the total function value of city $i$, in essence, it means the outward function provided by the employed people reflecting the outward degree of the total function value of city $i$, which is called urban flow tendency [25].

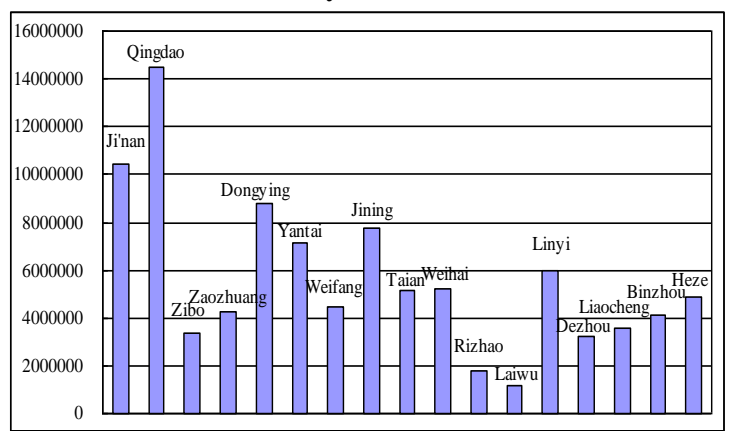

Fig.3 Urban flow intensity (Fi) of prefecture-level cities of Shandong urban agglomerations 


\section{B. Empirical analysis of the spatial economic relation of urban agglomeration}

\section{1)Analysis of urban flow intensity}

Columnar chart is formed by calculating the urban flow intensity with relevant data and see Fig.3. Urban flow intensity of Shandong urban agglomeration can be divided into three categories: high urban flow intensity city: Qingdao, Jinan; medium urban flow urban intensity city: Dongying, Jining, Yantai, Linyi; others are low urban flow intensity cities. The high value of urban flow intensity of Qingdao and Jinan indicate that they should become the two radiation core cities in Shandong urban agglomerations. As an important oil and gas producing city of Shandong, Dongying has higher urban flow intensity. As the entrance to Bohai Bay and facing Dalian across the sea, Yantai is an important port city to northward transportation. As regional central cities of urban agglomeration in south Shandong, Jining and Linyi have higher urban flow intensity value.

\section{2) Structural analysis of urban flow intensity}

From formula(5), $\mathrm{Fi}=\mathrm{GDPi} \times \mathrm{Ki}$, factors determin ing the urban flow intensity can be summarized into two factors: Comprehensive strength of the city and urban flow tendency and proportional relation of the two factors will influence the urban flow intensity.

$$
\begin{aligned}
& \text { Using formula(6),(7): } \\
G D P_{i}{ }^{\prime} & =G D P_{i} / \max G D P_{i} \\
K_{i}{ }^{\prime} & =K_{i} / \max K_{i}
\end{aligned}
$$

columnar charts of GDPi' and Ki' concerning the economic space of Shandong urban agglomeration is obtained and as showed in Fig.4. According to Fig.4, Qingdao, Jinan and Yantai are more outstanding in economic strength in terms of urban flow tendency. As regional core cities, their urban comprehensive strength should be improved to make their urban power match with their urban flow tendency. Zaozhuang, Dongying, Jining, Tai'an, Weihai, Rizhao, Laiwu, Dezhou, Liaocheng, Binzhou and Heze show higher urban flow tendency rather than urban power but the improvement of urban overall strength does not bring more economic benefit.

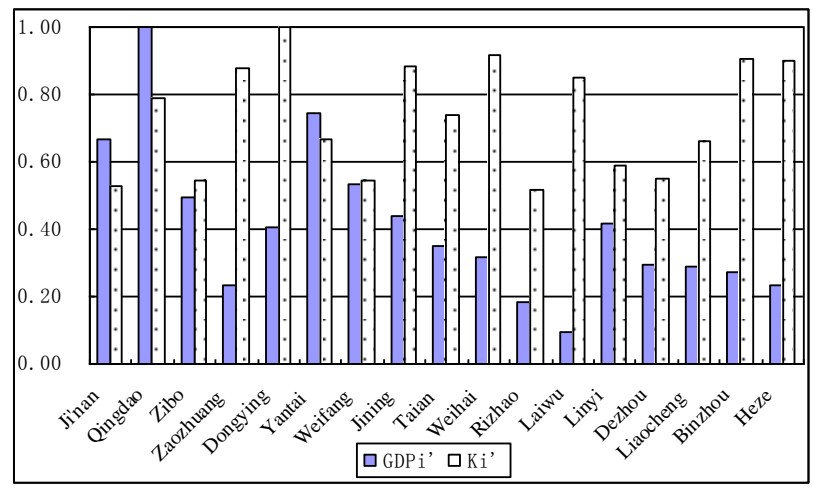

Fig.4 Urban flowintensity of prefecture-level cities of Shandong urban groups

\section{Urban function structure of Shandong urban groups \\ 1) Method and data}

\begin{tabular}{|c|c|c|c|}
\hline First industry & $\begin{array}{c}\text { Second industry } \\
\text { (1)Mining } \\
\text { industry } \\
\end{array}$ & $\begin{array}{c}\text { (2)Manufacturi } \\
\text { ng }\end{array}$ & $\begin{array}{c}\text { (3)Constructio } \\
\text { n }\end{array}$ \\
\hline $\begin{array}{c}\text { Dongying } 4.35 ; \\
\text { Dezhou } 3.26 ; \\
\text { Heze 2.66; } \\
\text { Zaozhuang } \\
\text { 2.29; Linyi } 1.84\end{array}$ & $\begin{array}{l}\text { Dongying } 153.33 \text {; } \\
\text { Jining } 102.21 ; \\
\text { Zaozhuang } 98.43 \text {; } \\
\text { Taian } 32.42 ; \\
\text { Laiwu26.88 }\end{array}$ & $\begin{array}{c}\text { Weihai 97.54; } \\
\text { Binzhou 92.04; } \\
\text { Qingdao 81.59; } \\
\text { Yantai 67.27; } \\
\text { Laiwu60.94 }\end{array}$ & $\begin{array}{c}\text { Taian } 50.45 ; \\
\text { Ji'nan37.14; } \\
\text { Linyi } 33.26 ; \\
\text { Zibo 21.75; } \\
\text { Zaozhuang } \\
21.64\end{array}$ \\
\hline $\begin{array}{c}\text { Third industry } \\
\text { (1)Transportati } \\
\text { on, storage and } \\
\text { postal service }\end{array}$ & $\begin{array}{l}\text { (2)Information } \\
\text { transmission, } \\
\text { computer service } \\
\text { and software }\end{array}$ & $\begin{array}{c}\text { (3)Wholesale } \\
\text { and retail }\end{array}$ & $\begin{array}{l}\text { (4) Accommoda } \\
\text { tion and } \\
\text { catering }\end{array}$ \\
\hline $\begin{array}{c}\text { Rizhao 14.49; } \\
\text { Ji’nan } 13.92 ; \\
\text { Qingdao } 8.18 ; \\
\text { Liaocheng } \\
4.40 ; \text { Yantai } \\
3.15 \\
\end{array}$ & $\begin{array}{c}\text { Ji'nan3.68; Linyi } \\
\text { 3.57; Rizhao 2.05; } \\
\text { Dongying 1.90; } \\
\text { Dezhou } 1.76\end{array}$ & $\begin{array}{c}\text { Ji’nan 13.77; } \\
\text { Taian 7.53; } \\
\text { Dezhou 6.69; } \\
\text { Weifang 6.23; } \\
\text { Rizhao 5.65 }\end{array}$ & $\begin{array}{c}\text { Ji’nan6.17; } \\
\text { Dongying 3.25; } \\
\text { Weihai 2.79; } \\
\text { Qingdao 2.41; } \\
\text { Taian } 1.02\end{array}$ \\
\hline $\begin{array}{l}\text { (5)Financial } \\
\text { industry }\end{array}$ & (6)Real estate & $\begin{array}{c}\text { (7)Leasing and } \\
\text { business } \\
\text { service }\end{array}$ & $\begin{array}{c}\text { (8)Scientific } \\
\text { research, } \\
\text { technology } \\
\text { service and } \\
\text { geological } \\
\text { prospecting } \\
\text { industry } \\
\end{array}$ \\
\hline $\begin{array}{c}\text { Liaocheng } \\
\text { 10.69; Linyi } \\
6.08 ; \text { Rizhao } \\
\text { 5.95; } \\
\text { Ji’nan5.90; } \\
\text { Jining } 5.56\end{array}$ & $\begin{array}{c}\text { Laiwu5.16; Yantai } \\
\text { 3.40; Qingdao } \\
\text { 3.32; Ji'nan3.23; } \\
\text { Weihai } 1.51\end{array}$ & $\begin{array}{c}\text { Ji'nan5.72; } \\
\text { Rizhao 4.74; } \\
\text { Taian 1.93; } \\
\text { Yantai } 0.97 ; \\
\text { Liaocheng } 0.96\end{array}$ & $\begin{array}{c}\text { Dongying } 7.74 ; \\
\text { Ji'nan3.98; } \\
\text { Qingdao 1.90; } \\
\text { Weifang } 0.98 ; \\
\text { Yantai } 0.93\end{array}$ \\
\hline $\begin{array}{c}\text { (9)Water } \\
\text { conservation, } \\
\text { environment } \\
\text { and public } \\
\text { facility } \\
\text { management }\end{array}$ & (10)Education & $\begin{array}{l}\text { (11)Health, } \\
\text { social security } \\
\text { and social } \\
\text { welfare }\end{array}$ & $\begin{array}{c}\text { (12)Culture, } \\
\text { sports and } \\
\text { entertainment }\end{array}$ \\
\hline $\begin{array}{c}\text { Heze } 4.87 ; \\
\text { Zaozhuang } \\
2.50 ; \text { Jining } \\
\text { 2.22; Dezhou } \\
\text { 1.95; Liaocheng } \\
1.90\end{array}$ & $\begin{array}{c}\text { Heze } 44.88 \text {; Linyi } \\
23.45 \text {; Liaocheng } \\
22.25 \text {; Dezhou } \\
21.62 ; \text { Weifang } \\
20.96\end{array}$ & $\begin{array}{c}\text { Heze 16.37; } \\
\text { Liaocheng } \\
\text { 10.86; Weifang } \\
\text { 10.73; Linyi } \\
\text { 9.24; Rizhao } \\
6.27\end{array}$ & $\begin{array}{c}\text { Ji’nan2.46; } \\
\text { Heze 1.02; Zibo } \\
\text { 0.96; Qingdao } \\
\text { 0.86; Rizhao } \\
0.77\end{array}$ \\
\hline
\end{tabular}

T ABLE.3 STATISTICAL TABLE OF TOP 5 INDUSTRIAL FUNCTION INDEX OF CITIES OF SHANDONG URBAN AGGLOMERATION

The concept of function index was put forward by J.W.Webb in an essay when studying a small town of Minnesota, America and its expression is(8):

$$
\text { Functionindex }=P \times \frac{P}{M P} \times 100 \%
$$


In Formula(8), $\mathrm{P}$ represents the percentage of the employed population of some economic sector of the city's total population of; MP represents the percentage of the employed population of some economic sector of the total provincial employed population. From the expression, it can tell that $\mathrm{P} / \mathrm{PM}$ is the calculation method for location quotient; therefore, function index not only reflects the regional position of some sector but also reflects the urban position of the section. The essay selects the employed population data of 18 industries from 17 prefecture-level cities in Shandong province in 2011 and conducts relevant calculation by Formula(8).

\section{2) Calculation of urban function index}

The calculation result of urban function index among cities of Shandong urban agglomeration is showed in TABLE.3. In order to visually show the result, TABLE. 3 only listed the data of the top 5 function index among different industries and the value following each city represents the function index. From TABLE.3, it can tell that the calculation result of function index has great similarity to the current industrial structure of each city.

\section{CONCLUSION AND SUGGESTION}

Firstly, in the economic space of Shandong urban agglomerations, Jinan and Qingdao, the two core cities, are in the monopoly position. Viewing the whole urban grade and scale structure, the lack of small cities in the economic space in Shandong urban agglomerations leads to the upward piling of urban grade and scale and cannot give full play to the industrial transfer and radiation role of the large cities. Meanwhile, the weak radiation and leading role of s mall and medium cities cannot attract more labors and therefore fail to help lessen the population pressure for the large cities.

Secondly, viewing the spatial attraction of the urban agglomeration, only the city group along Jinan to Qingdao railway has been developed while city group in south Shandong is not developed yet, which is unfavorable for the full play of the overall function of Shandong urban agglomeration economic space. Furthermore, radiation effect to Yantai, Weihai and Rizhao from Shandong peninsular and Qingdao is not obvious and one-hour distance economic circle planned by peninsular area is not realized in the spatial attraction mode, which needs further improvement.

Thirdly, the urban function is divided in some degree but the division is undefined. Most cities are integration and industry and business orientated with similar urban function where specialized leading urban function is not obvious and the overall function is weak. For instance, in transportation and storage industry, Qingdao is an important port city in China, but its urban function index only ranks third and its finance even did not edge in the top five.

Last but not least, from the relation of the economic spatial function of the urban agglomeration, Shandong urban agglomeration tends to be outward in terms of economic space. Compared with other domestic cities at the same period, it has higher urban flow intensity. By further analy zing the urban flow structure of Shandong urban agglomeration economic space, it can be also found that Qingdao and Jinan are core cities with high urban flow intensity and strong economy but they are weak in comprehensive service; the outstanding issue faced by other regional cities is the overall weak economy.

Through the analysis, urban agglomerations off Shandong Province have basically taken shape which are developing in bipolar direction centered at Jinan and Qingdao, while South Shandong economic belt has not formed yet and more attention should be attached to the development of South Shandong. Given that the radiation influence of Shandong peninsular economic belt is not obvious, rail transit development of the one-hour distance economic circle should be strengthened to break up the spatial obstacle. It should accelerate the industrial structure adjustment to form a specialized industrial layout with distinct features.

\section{REFERENCES}

[1] Zhou Yixing, Urban Geography [M]. Beijing: Commercial Press, 1995 315. (in Chinese)

[2] Li Yining, New Idea for Regional Development [M]. Beijing: Economic Daily Press, 2000.(in Chinese)

[3] Ullman E.L. American Commodity Flow[M]. Seattle: University of Washingt on Press, 1957.

[4] J.Gottmann.Megalopolis:or the Urbanization of the Northeastern Seaboard[J].Economic Geography, 1957.

[5] McGeeT G.The Emergence or Desakota Regions in Asia: Expanding a Hypothesis[M].Honolulu:University of Hawail Press, 1991.

[6] FridemanJR. Urbanization, Planning and National Development[M] London: Sage Publication, 1973.

[7] Gustavo Garza. Global economy, metropolitan dynamics and urban policies in Mexied [J].Cities, 1999.

[8] G.Mulgan. Communication and control: net works and the new economics of communication[M]. Oxford:Policy Press, 1991.

[9] [9]Tomita Kazuaki, Structural Development of Megalopolis [M]. Tokyo: Ancient and Modern Academy, 1995. (in Chinese)

[10] Hong Jun, Ning Yuemin. Introduction to Urban Geography [M]. Hefei: Anhui Science Press, 1983: 314-324. (in Chinese)

[11] Zhou Yixing. Definition of Urban place and statistical standards of urban population in china: Problem and Solution [J].Asian Geography, 1988 (1): $12-18$.

[12] Lu Dadao. A study of the Best Regional Structure and Development and Overview and Reanalysis of "dot-axil" Theory and T Structure[J].Geographical Journal, 2001(2): 127-135. (in Chinese)

[13] Yao Shimou. Spatial Extension of China Metropolis [M]. Hefei: Press of University of Science and Technology of China, 1998: 33-65. (in Chinese)

[14] Zhu Yingming, Analysis of Urban Agglomeration Economic Space[M]. Beijing: Science Press, 2004. (in Chinese)

[15] Yao Shimou, Chen Shuang. The Trend of Urban Spatial Evolution in the Changjiang River Delta[J]. Acta Geographica Sinica. 1998(53):1-10. (in Chinese)

[16] Zhang Gongsheng. The construction of city agglomeration connotation, extension analysis and new city group[J]. Shandong Economy. 2008(4):36-39.(in Chinese)

[17] Shi Wujun.Study on the development model of ring space of Bohai city group [J]. Economic Outlook The Bohai Sea. 2011(10):5.(in Chinese)

[18] Sun Jinfang, Ma Zuqi, Wang Hui. Spatial Analysis on Structural Characteristics of Shandong Peninsula Urban Agglomeration[J].Urban Studies. 2009(6):47-52. (in Chinese)

[19] Xie Fuhui. Study on Spatial Structure Evolution of Shandong Peninsula Urban Agglomerations [D].Nanjing University of Aeronautics and Astronautics.2006.(in Chinese) 
[20] Sun Xiaona. The evolution of the spatial structure of Shandong peninsula city group analysis[J]. Economic Research Guide. 2009(23):48 -49.(in Chinese)

[21] Wang Xinna. Study on Urban Cluster Spatial Structure in Shandong Peninsula[J].Resources \& Industries. 2008,10(3):63-66. (in Chinese)

[22] Yuan Angui. Research on the Development of Chengdu-Chongqing Urban Agglomeration Economic space[D]. Southwestern University of Finance and Economics. 2008.P74,P79.(in Chinese)
[23] Chen Yanguang, Zhou Yixing. A Study of Multifractal Measures of the Spatial Structure of the Urban System in Central Plains[J].Acta Scicentiarum Naturalum Universitis Pekinesis. 2001, 37(6): 810-818.(in Chinese)

[24] Zhu Yingming, Yu Nianwen. Urban flows in the HuNingHang Urban Compact District[J].Urban Planning Forum. 2002(1):31-33.(in Chinese)

[25] Zhang Hong-ou,Ye Yuyao,Luo Xiaoyun, Ye Shuning. Research on the Degree of the Urban Flow of Pearl River Delta[J].Areal Research and Development.2004,23(6): 53-56.(in Chinese) 